\title{
The extent of papillary muscle approximation affects mortality and durability of mitral valve repair for ischemic mitral regurgitation
}

\author{
Satoru Wakasa, Suguru Kubota, Yasushige Shingu, Tomonori Ooka, Tsuyoshi Tachibana and Yoshiro Matsui
}

\begin{abstract}
Background: Since reduction annuloplasty alone for ischemic mitral regurgitation (MR) cannot prevent late recurrence of MR or improve survival for those with left ventricular (LV) dysfunction, and the surgical approach to this etiology is still controversial, we conducted a study to assess the efficacy of the additional papillary muscle approximation (PMA) procedure for ischemic MR by comparing the different subtypes of PMA.

Methods: We studied 45 patients who underwent mitral annuloplasty and papillary muscle approximation (PMA) for ischemic MR between 2003 and 2012. Papillary muscles were approximated entirely (CPMA: complete PMA, $n=32$ ) through an LV incision or partially from the tips to mid-parts (iPMA: incomplete PMA, $n=13$ ) through the mitral and aortic valves. Twenty-three patients with CPMA also underwent LV plasty (LVP). We assessed the outcomes after PMA by comparing CPMA and IPMA.

Results: The baseline MR grade, NYHA class, LV end-diastolic diameter, and LV ejection fraction (LVEF) were $2.8 \pm 1.0,3.2 \pm 0.6,67 \pm 6 \mathrm{~mm}$, and $30 \pm 10 \%$, respectively. There were no significant differences in these parameters among those with iPMA, CPMA/LVP-, and CPMA/LVP+, though iPMA patients had better LVEF than others. Three patients died before discharge and 12 died during the follow-up. Recurrence of grade $2+$ and $3+$ MR occurred in 8 and 2 patients, respectively. Reoperation for recurrent MR was performed only for the 2 patients with recurrence of grade $3+$ MR. The $C P M A$ was associated with lower mortality (log-rank $P=0.020$ ) and a lower rate of recurrence of $M R \geq 2+$ (log-rank $P=0.005$ ) than iPMA. In contrast, there were no significant differences in the mortality (log-rank $P=0.45$ ) and rate of recurrence (log-rank $P=0.98$ ) between those with CPMA/LVP- and CPMA/LVP+. The 4-year survival rate and rate of freedom from recurrence of $M R \geq 2+$ were $83 \%$ and $85 \%$ for those with CPMA, repectively. In contrast, the rates were $48 \%$ and $48 \%$ for those with iPMA, respectively.
\end{abstract}

Conclusions: Complete PMA could be associated with lower postoperative mortality and higher durability of mitral valve repair for ischemic MR.

Keywords: Cardiomyopathy, Ischemic heart disease, Mitral valve, Surgery

\section{Background}

Ischemic mitral regurgitation (MR) is a predictor of mortality in patients with ischemic heart failure [1]. This disease is predominantly caused by left ventricular (LV) remodeling and subsequent displacement of the papillary muscles [2], usually without structural valve lesions [3]. The displacement of the papillary muscles

\footnotetext{
*Correspondence: ymatsui@med.hokudai.ac.jp

Department of Cardiovascular and Thoracic Surgery, Hokkaido University Graduate School of Medicine, Kita-15, Nishi-7, Kita-ku, Sapporo 060-8638, Japan
}

results in tethering of the mitral valve that is associated with increased stiffness of the mitral valve leaflet and loss of the normal leaflet opening and closure [4]. Since Bolling and Bach first reported the efficacy of reduction annuloplasty [5], this procedure has been the gold standard of surgical treatment for ischemic MR. However, annuloplasty alone cannot provide a survival benefit for those with LV dysfunction [6], and is associated with a high prevalence of late recurrence of MR [7], which is an important predictor of mortality after surgery for ischemic MR [8]. Reduction annuloplasty may 
exaggerate posterior leaflet tethering due to an anterior shift of the posterior annulus by the ring and result in recurrence of MR late after the annuloplasty [9]. Thus, the mitral valve procedure alone could be insufficient to treat ischemic MR because this is a ventricular disease rather than a valvular disease, and additional ventricular and submitral procedures could be beneficial. We adopted a submitral procedure named papillary muscle approximation (PMA) as a radical procedure for ischemic MR with severe LV dysfunction. In this procedure, we approximate the papillary muscles entirely or partially depending on the patient's condition. We hypothesized that PMA could improve the survival and durability of mitral valve repair and the extent of approximation could affect the outcomes. We assessed the efficacy of this procedure by comparing the different subtypes of PMA.

\section{Methods}

\section{Study design}

Between 2003 and 2012, papillary muscle approximation was performed for 127 patients with functional MR, of whom 70 underwent this procedure for ischemic MR. Among them, 45 patients were studied after exclusion of 25 patients due to the following reasons: lack of follow-up echocardiographic data $(n=16)$, PMA performed as reoperation $(\mathrm{n}=3)$, with a concomitant left ventricular assist device $(n=1)$, with another leaflet procedure $(n=1)$ or posterior left ventricuoplasty $(n=5)$. All data were collected retrospectively from medical records and our database. The study protocol was approved by the Institutional Review Board of the Hokkaido University Hospital for Clinical Research.

\section{Examinations of cardiac parameters}

Echocardiography was performed within 1 week before surgery and repeated before discharge at $0.9 \pm 0.7$ months (range, 0.2 to 4.2 months) after surgery. After discharge, follow-up echocardiography was performed regularly on an outpatient basis. The latest echocardiographic study was performed at a mean follow-up time of $2.6 \pm 2.2$ years. The following cardiac parameters were acquired: LV enddiastolic diameter, LV end-systolic diameter, LV ejection fraction (LVEF), MR grade, deceleration time, coaptation height of the mitral valve, and interpapillary muscle distance. The LV end-diastolic and end-systolic diameters were measured by M-mode transthoracic echocardiography. The LVEF was calculated by the modified Simpson method. The severity of MR was graded based on color Doppler images as follows: $1+$, mild; $2+$, moderate; $3+$, moderately severe; and $4+$, severe [10]. The deceleration time of the early transmitral flow velocity was measured on an apical long-axis color Doppler flow image. The coaptation height of the mitral valve was measured in 2and 4-chamber apical views in mid-systole by B-mode transthoracic echocardiography [11]. The interpapillary muscle distance was also measured in the short axis view at the papillary muscle level in end-diastole [12]. Mitral valve tethering was defined as significant if the coaptation height of the mitral valve was $\geq 10 \mathrm{~mm}$ or interpapillary muscle distance was $\geq 30 \mathrm{~mm}$. The $\mathrm{LV}$ end-systolic volume was evaluated in 40 (89\%) patients using echocardiography $(\mathrm{N}=12,30 \%)$, quantitative gated scintigraphy $(\mathrm{N}=17$, $43 \%)$, magnetic resonance imaging $(\mathrm{N}=2,5 \%)$ and left ventriculography $(\mathrm{N}=9,22 \%)$.

\section{Operative procedures}

All the procedures were performed through a median sternotomy. Cardiopulmonary bypass was commenced through the ascending aorta and both vena cavae. After aortic cross clamping, blood cardioplegia was administrated and cardiac arrest was obtained. Subsequent procedures were performed under moderate hypothermia. Mitral annuloplasty was performed for all the patients who were indicated for PMA. We used a true-sized semi-rigid (Physioring or Physioring II, Edwards Lifesciences, Irvine, CA, USA) or rigid (Rigid Saddle Annuloplasty Ring, St. Jude Medical, Inc., St Paul, MN, USA) annuloplasty ring. The patients with significant mitral valve tethering underwent PMA, which we adopted to correct tethering by gathering the papillary muscles that were displaced due to LV remodeling. The details of the procedure were described elsewhere [13]. The papillary muscles were entirely approximated side-byside (complete PMA) through an LV incision or partially from the tips to the mid-parts (incomplete PMA) through the mitral or aortic valve using pledgetted mattress sutures of 3-0 polypropylene (Figure 1 ). The method was selected based on the presence of a myocardial scar lesion on the anterior LV wall. If one existed, an LV incision was made on the anterior LV wall and complete PMA was performed. Otherwise, incomplete PMA without an LV incision was performed because entire approximation through the cardiac valves is technically difficult, especially at the bases of papillary muscles. The presence of a myocardial scar was evaluated preoperatively using quantitative gated scintigraphy, positron emission tomography, or magnetic resonance imaging. The LV was closed after complete PMA with direct suturing or concomitant left ventriculoplasty (LVP), if indicated.

The patients with severe LV dilatation (end-diastolic diameter $\geq 65 \mathrm{~mm}$ ) and a broad anterior myocardial scar underwent overlapping left ventriculoplasty, which was developed as a radical procedure to reduce the LV volume and restore the LV shape and function. The details of the procedure were described elsewhere [14]. Papillary muscle suspension was adopted from 2005 to reinforce the effect of PMA by suspending the approximated tips of the papillary muscles to the mitral annulus using 4-0 polytetrafluoroethylene sutures. Initially, the suspension 


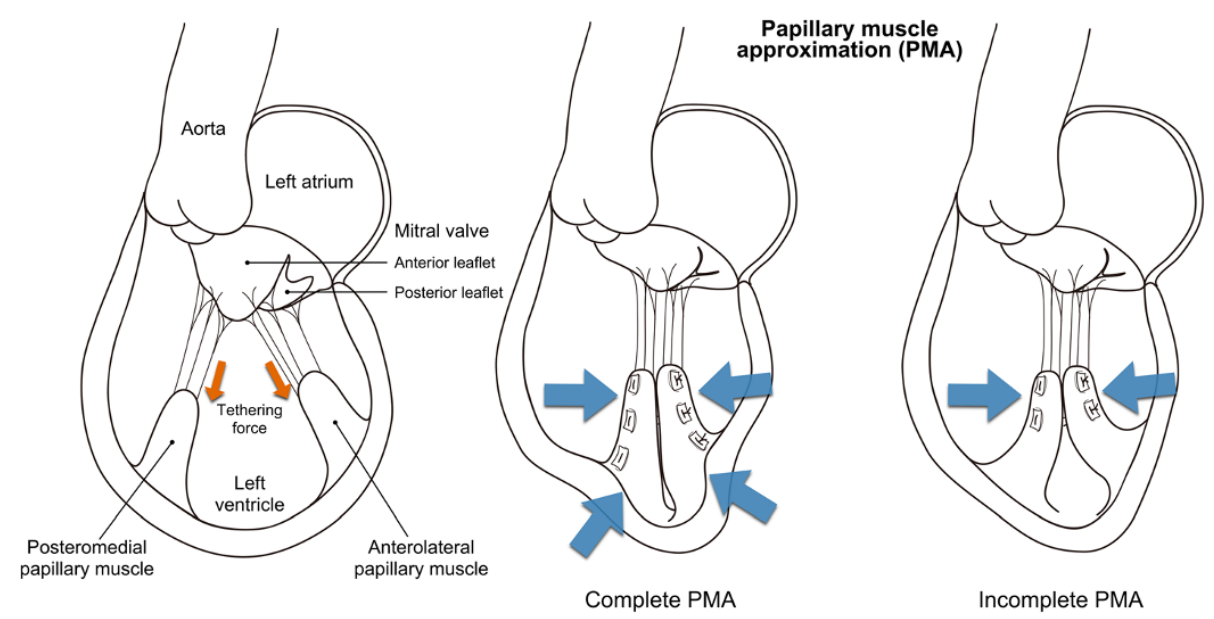

Figure 1 Schematic of complete and incomplete papillary muscle approximation procedures.

was performed toward the posterior mitral annulus against apical tethering, though anterior suspension became predominant from 2008, aiming at reduction of posterior tethering. Coronary artery bypass grafting was performed if the patient had untreated and significant coronary lesions. The Maze procedure and tricuspid annuloplasty were performed when needed. Tricuspid annuloplasty was indicated even for mild regurgitation if the patients had severely deteriorated LV function or pulmonary hypertension. Perioperative hemodynamic instability refractory to medical control was treated with percutaneous cardiopulmonary support and intraaortic balloon pumping.

\section{Statistical analyses}

Continuous variables are expressed as mean \pm standard deviation and categorical variables as numbers and percentages. Preoperative and postoperative data were compared using the Wilcoxon signed-rank test. Comparisons among 3 groups were conducted using the Kruskal-Wallis test for continuous data. Post hoc tests were performed using the Mann-Whitney U test with Bonferroni's correction. Categorical data were compared using the chi-square test or Fisher's exact test, if appropriate. Postoperative mortality and freedom from recurrence of MR were estimated using the Kaplan-Meier method, and differences among groups were assessed by the log-rank test. A twosided $P$ value $<0.05$ was considered to indicate statistical significance in all the tests. All analyses were performed using IBM SPSS Statistics (version 20, IBM Corporation, Somers, NY, USA).

\section{Results}

Patients' baseline characteristics

Table 1 shows the patients' baseline characteristics. The mean age of the study subjects was $62 \pm 12$ (range, 32 to $85)$ years and $38(84 \%)$ were male. The baseline New York
Heart Association (NYHA) functional class was III/IV for 39 (87\%) patients. Complete PMA without LVP was associated with younger age. Coronary artery lesions and the severity of heart failure did not significantly differ among the 3 groups.

\section{Surgical procedures}

Table 2 summarizes the operative procedures. Mitral annuloplasty was perforemed for all the patients. Complete and incomplete PMA were performed for $32(71 \%)$ and 13 (29\%) patients, respectively. Twenty-three (72\%) of those with complete PMA underwent concomitant LVP. All the patients with LVP underwent overlappling left ventriculoplasty. Papillary muscle suspension was performed for 24 (53\%) patients. Anterior and posterior suspension were performed for 14 and 8 patients, respectively. Coronary artery bypass was performed for 41 (91\%) patients.

\section{Cardiac sizs and function}

Table 3 summarizes the perioperative cardiac sizes and functions. The baseline LV size, MR grade, and severity of mitral valve tethering did not significantly differ among the 3 groups. However, incomplete PMA was associated with better baseline LVEF. Postoperatively, the LV size, MR grade, coaptation height, and interpapillary muscle distance decreased significantly for all 3 groups. The LVEF significantly increased for those with complete PMA, though there was no significant change in LVEF for those with incomplete PMA (Figure 2). These postoperative parameters did not significantly differ among the 3 groups.

\section{Postoperative mortality}

Three patients died before discharge and 12 died during a mean follow-up time of $3.5 \pm 2.3$ years. Cardiac-related deaths were observed for 3,1 , and 4 patients, respectively $(P=0.78)$. Other non-cardiac causes of death were 
Table 1 Patients' baseline characteristics

\begin{tabular}{|c|c|c|c|c|}
\hline & \multirow{2}{*}{$\begin{array}{l}\text { Incomplete PMA } \\
\qquad(\mathrm{N}=13)\end{array}$} & \multicolumn{2}{|c|}{ Complete PMA } & \multirow{2}{*}{$\begin{array}{c}P \\
\text { Value }\end{array}$} \\
\hline & & LVP-(N=9) & $L V P+(N=23)$ & \\
\hline Age, years & $65 \pm 8$ & $50 \pm 14$ & $65 \pm 10$ & 0.024 \\
\hline Male, n (\%) & $11(85 \%)$ & $9(100 \%)$ & $18(78 \%)$ & 0.48 \\
\hline Hypertension, n (\%) & $8(62 \%)$ & $4(44 \%)$ & $7(30 \%)$ & 0.19 \\
\hline Dialysis, n (\%) & $2(15 \%)$ & $2(22 \%)$ & $2(9 \%)$ & 0.62 \\
\hline Diabetes, n (\%) & $7(54 \%)$ & $4(44 \%)$ & $10(44 \%)$ & 0.92 \\
\hline Atrial fibrillation, n (\%) & $2(15 \%)$ & 0 & $4(17 \%)$ & 0.53 \\
\hline History of VT, n (\%) & 0 & $1(11 \%)$ & $5(22 \%)$ & 0.21 \\
\hline \multicolumn{5}{|l|}{ Coronary lesions, n (\%) } \\
\hline Left anterior descending & $12(92 \%)$ & $8(89 \%)$ & $23(100 \%)$ & 0.23 \\
\hline Left circumflex & $12(92 \%)$ & $8(89 \%)$ & $16(70 \%)$ & 0.26 \\
\hline Right & $13(100 \%)$ & 7 (78\%) & $18(78 \%)$ & 0.13 \\
\hline NYHA class, n (\%) & & & & 0.43 \\
\hline$\|$ & $3(23 \%)$ & $2(22 \%)$ & $1(4 \%)$ & \\
\hline III & $6(46 \%)$ & $5(56 \%)$ & $14(61 \%)$ & \\
\hline IV & $4(31 \%)$ & $2(22 \%)$ & $8(35 \%)$ & \\
\hline Inotrope, n (\%) & $2(15 \%)$ & $1(11 \%)$ & $3(13 \%)$ & 1.0 \\
\hline Urgent, n (\%) & $2(15 \%)$ & 0 & $2(9 \%)$ & 0.65 \\
\hline IABP, n (\%) & $2(15 \%)$ & 0 & $6(26 \%)$ & 0.26 \\
\hline PCPS, n (\%) & 0 & 0 & $1(4 \%)$ & 1.0 \\
\hline
\end{tabular}

PMA = papillary muscle approximation, LVP = left ventriculoplasty, VT = ventricular tachyarrhythmia, NYHA = New York Heart Association, IABP = intraaortic balloon pumping, PCPS = percutaneous cardiopulmonary support.

Table 2 Operative procedures

\begin{tabular}{|c|c|c|c|c|}
\hline & \multirow{2}{*}{$\begin{array}{c}\text { Incomplete PMA } \\
(\mathrm{N}=13)\end{array}$} & \multicolumn{2}{|c|}{ Complete PMA } & \multirow[t]{2}{*}{ P Value } \\
\hline & & LVP-(N=9) & $L V P+(N=23)$ & \\
\hline Mitral annuloplasty, n (\%) & $13(100 \%)$ & $9(100 \%)$ & $23(100 \%)$ & N/A \\
\hline Ring size, n (\%) & & & & 0.30 \\
\hline $24 \mathrm{~mm}$ & 0 & 0 & $1(4 \%)$ & \\
\hline $26 \mathrm{~mm}$ & $6(46 \%)$ & $6(67 \%)$ & $17(74 \%)$ & \\
\hline $28 \mathrm{~mm}$ & $6(46 \%)$ & $3(33 \%)$ & $3(13 \%)$ & \\
\hline $30 \mathrm{~mm}$ & $1(8 \%)$ & 0 & $2(9 \%)$ & \\
\hline PMA, n (\%) & & & & $<0.001$ \\
\hline Complete PMA & 0 & $9(100 \%)$ & $23(100 \%)$ & \\
\hline Incomplete PMA & $13(100 \%)$ & 0 & 0 & \\
\hline PM suspension, n (\%) & & & & 0.29 \\
\hline None & $5(39 \%)$ & $3(33 \%)$ & $15(65 \%)$ & \\
\hline Anterior & $6(46 \%)$ & $3(33 \%)$ & $5(22 \%)$ & \\
\hline Posterior & $2(15 \%)$ & $3(33 \%)$ & $3(13 \%)$ & \\
\hline Overlapping left ventriculoplasty, n (\%) & 0 & 0 & $23(100 \%)$ & $<0.001$ \\
\hline CABG, n (\%) & $13(100 \%)$ & $8(89 \%)$ & 20 (87\%) & 0.41 \\
\hline TAP, n (\%) & $9(75 \%)$ & $4(44 \%)$ & 17 (74\%) & 0.34 \\
\hline Maze, n (\%) & $1(8 \%)$ & 0 & $2(9 \%)$ & 1.0 \\
\hline
\end{tabular}

PMA = papillary muscle approximation, $\mathrm{LVP}=$ left ventriculoplasty, $\mathrm{PM}=$ papillary muscles, $\mathrm{CABG}=$ coronary artery bypass grafting, $\mathrm{AVR}=$ aortic valve replacement, $\mathrm{TAP}=$ tricuspid annuloplasty, $\mathrm{AVR}=$ aortic valve replacement. 
Table 3 Perioperative cardiac sizes and functions

\begin{tabular}{|c|c|c|c|c|c|c|}
\hline & \multirow{2}{*}{$\begin{array}{l}\text { Incomplete } \\
\text { PMA (A) }\end{array}$} & \multirow{2}{*}{$\begin{array}{c}\text { Complete } \\
\text { PMA/LVP- (B) }\end{array}$} & \multirow{2}{*}{$\begin{array}{c}\text { Complete } \\
\text { PMA/LVP+ (C) }\end{array}$} & \multicolumn{3}{|c|}{$P$ valuest } \\
\hline & & & & A vs. $B$ & A vs. $C$ & B vs. C \\
\hline \multicolumn{7}{|c|}{ Preoperative values } \\
\hline LVDd, mm & $66 \pm 5$ & $65 \pm 5$ & $68 \pm 7$ & 1.0 & 1.0 & 0.64 \\
\hline LVDs, mm & $55 \pm 7$ & $57 \pm 6$ & $58 \pm 8$ & 1.0 & 0.42 & 1.0 \\
\hline LVESVI, $\mathrm{ml} / \mathrm{m}^{2}$ & $95 \pm 24$ & $112 \pm 26$ & $117 \pm 46$ & 0.74 & 0.50 & 1.0 \\
\hline LVEF, \% & $35 \pm 9$ & $28 \pm 4$ & $27 \pm 10$ & 0.05 & 0.039 & 0.84 \\
\hline MR grade & $2.8 \pm 1.0$ & $2.9 \pm 1.1$ & $2.8 \pm 1.1$ & 1.0 & 1.0 & 1.0 \\
\hline $\mathrm{DCT}, \mathrm{ms}$ & $208 \pm 71$ & $159 \pm 47$ & $151 \pm 44$ & 0.39 & 0.09 & 1.0 \\
\hline IPMD, mm & $31 \pm 7$ & $28 \pm 4$ & $29 \pm 5$ & 0.71 & 1.0 & 1.0 \\
\hline $\mathrm{CH}(2 \mathrm{CV}), \mathrm{mm}$ & $11 \pm 2$ & $9 \pm 2$ & $10 \pm 2$ & 0.26 & 0.24 & 1.0 \\
\hline $\mathrm{CH}(4 \mathrm{CV}), \mathrm{mm}$ & $9 \pm 2$ & $10 \pm 3$ & $10 \pm 2$ & 1.0 & 1.0 & 1.0 \\
\hline \multicolumn{7}{|c|}{ Postoperative values } \\
\hline LVDd, mm & $57 \pm 6^{* *}$ & $58 \pm 4^{* *}$ & $63 \pm 8^{* *}$ & 1.0 & 0.06 & 0.23 \\
\hline LVDs, mm & $48 \pm 7^{* *}$ & $48 \pm 6^{* *}$ & $51 \pm 11^{* *}$ & 1.0 & 0.35 & 0.61 \\
\hline LVESVI, $\mathrm{ml} / \mathrm{m}^{2}$ & $64 \pm 14^{* *}$ & $78 \pm 25^{*}$ & $70 \pm 26^{* *}$ & 0.90 & 1.0 & 1.0 \\
\hline LVEF, \% & $34 \pm 10$ & $33 \pm 7^{*}$ & $39 \pm 14^{* *}$ & 1.0 & 0.78 & 0.85 \\
\hline MR grade & $0.4 \pm 0.5^{* *}$ & $0.3 \pm 0.4^{* *}$ & $0.4 \pm 0.7^{* *}$ & 1.0 & 1.0 & 1.0 \\
\hline $\mathrm{DCT}, \mathrm{ms}$ & $274 \pm 61^{*}$ & $205 \pm 70$ & $207 \pm 60^{*}$ & 0.25 & 0.06 & 1.0 \\
\hline IPMD, mm & $10 \pm 7^{* *}$ & $7 \pm 7^{*}$ & $5 \pm 6^{* *}$ & 1.0 & 0.32 & 1.0 \\
\hline $\mathrm{CH}(2 \mathrm{CV}), \mathrm{mm}$ & $5 \pm 3^{*}$ & $4 \pm 3^{*}$ & $3 \pm 3^{* *}$ & 1.0 & 1.0 & 1.0 \\
\hline $\mathrm{CH}(4 \mathrm{CV}), \mathrm{mm}$ & $4 \pm 3^{* *}$ & $4 \pm 2^{*}$ & $4 \pm 3^{* *}$ & 1.0 & 1.0 & 1.0 \\
\hline
\end{tabular}

$\mathrm{PMA}=$ papillary muscle approximation, $\mathrm{LVP}=$ left ventriculoplasty, $\mathrm{LV}=$ left ventricle, $\mathrm{LVDd}=\mathrm{LV}$ end-diastolic diameter, $\mathrm{LVEF}=\mathrm{LV}$ ejection fraction, $\mathrm{LVESVI}=\mathrm{LV}$ end-systolic volume index, $\mathrm{MR}=$ mitral regurgitation, $\mathrm{DCT}=$ deceleration time, IPMD = interpapillary muscle distance, $\mathrm{CH}=\mathrm{Coaptation}$ height of the mitral valve, $2 \mathrm{CV}=2$-chamber apical view, $4 \mathrm{CV}=4$-chamber apical view.

†Bonferroni corrected $\mathrm{P}$.

${ }^{*} \mathrm{P}<0.05$ or ${ }^{* *} \mathrm{P}<0.01$ compared with preoperative values.

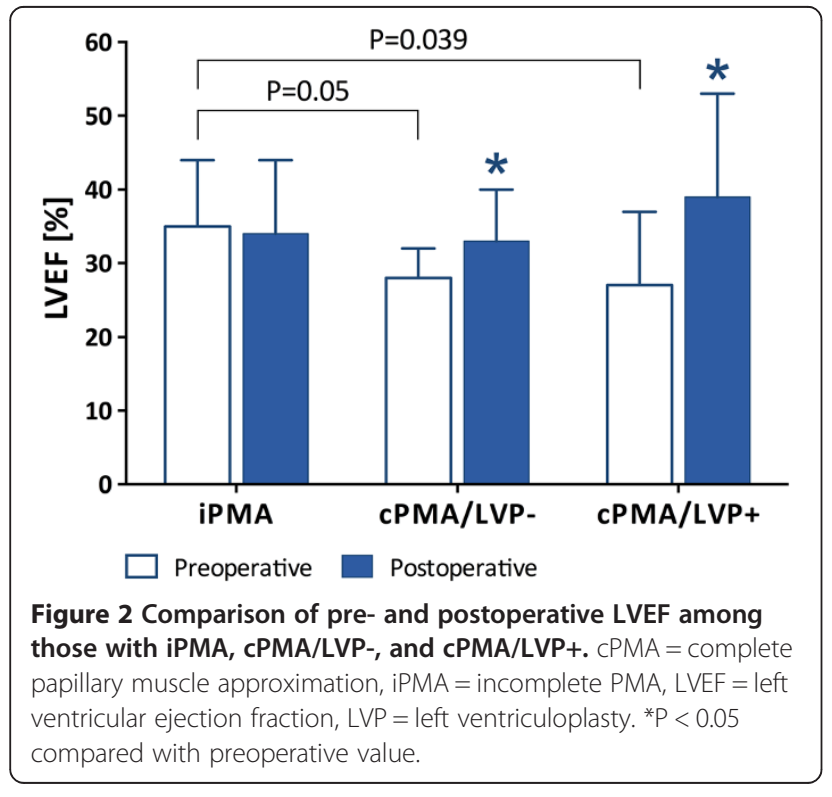

septicemia for 4 , bowel ischemia for 1 , stroke for 1 , and suicide for 1 . Hospital mortality rates were $15 \%, 0 \%$, and $4.3 \%$ for those with incomplete PMA, complete PMA/ LVP-, and complete PMA/LVP+, respectively $(\mathrm{P}=0.42)$. The postoperative mortality was significantly different between those with complete and incomplete PMA (log-rank $\mathrm{P}=0.020$, Figure $3 \mathrm{~A}$ ). The 1-, 2-, and 4-year survival rates were $90 \%, 87 \%$, and $83 \%$ for those with complete PMA, respectively. In contrast, those rates were $83 \%, 75 \%$, and $48 \%$ for those with incomplete PMA, respectively. Concomitant LVP and papillary muscle suspension did not affect mortality. There was no significant difference in mortality between those with complete PMA/LVP + and complete PMA/LVP- (log-rank $\mathrm{P}=0.45$, Figure $3 \mathrm{~B}$ ) or among those with anterior papillary muscle suspension, posterior suspension, and without suspension (log-rank $\mathrm{P}=0.48)$.

The postoperative NYHA functional class was class II or less in all but 3 patients with class III and did not significantly differ among the 3 groups $(P=0.76)$. At the latest follow-up, most (88\%) of the patients had NYHA functional class II or less. 

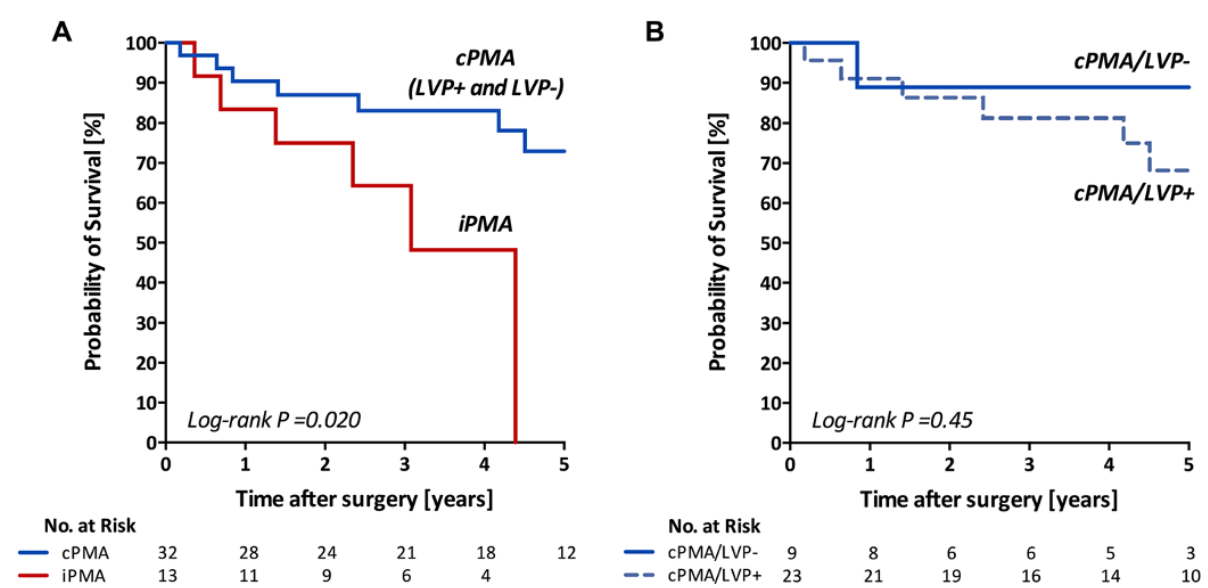

Figure 3 Comparison of survival between complete and incomplete papillary muscle approximation procedures (A), and complete papillary muscle approximation with and without left ventriculoplasty (B). CPMA = complete papillary muscle approximation, iPMA = incomplete PMA, LVP = left ventriculoplasty.

\section{Recurrence of MR}

Recurrence of $M R \geq 2+$ was observed in 10 patients, of whom only 2 had grade $3+$. No patient had grade $4+$ recurrence. Reoperation for recurrent MR was performed for the 2 patients with recurrence of grade $3+$ MR. One had incomplete PMA and presented recurrent MR due to infective endocarditis and underwent mitral valve replacement with redo PMA 2 months after the initial operation. The other had early postoperative recurrence of MR after complete PMA due to dehiscence of the PMA sutures. He underwent redo PMA but died before discharge due to mediastinitis 17 months after the initial operation. Kaplan-Meier curves for the rate of recurrence of MR significantly differed between those with complete and incomplete PMA (log-rank $\mathrm{P}=0.005$, Figure $4 \mathrm{~A})$. The 1 -, 2-, and 4-year rates of freedom from recurrence were
93\%, 85\%, and 85\% for those with complete PMA, respectively. In contrast, those rates were $57 \%, 48 \%$, and $48 \%$ for those with incomplete PMA, respectively. Concomitant LVP and papillary muscle suspension did not affect the durability of the mitral valve repair. The rates of freedom from recurrence did not significantly differ between those with complete PMA/LVP- and complete PMA/ $\mathrm{LVP}+(\log$-rank $\mathrm{P}=0.98$, Figure $4 \mathrm{~B})$ or among those with different types of papillary muscle suspension (logrank $\mathrm{P}=0.43$ ).

\section{Discussion}

In this study, we assessed the results of PMA for ischemic MR and demonstrated that mitral valve repair with complete PMA was associated with a satisfactorily high postoperative survival rate and durability of repair
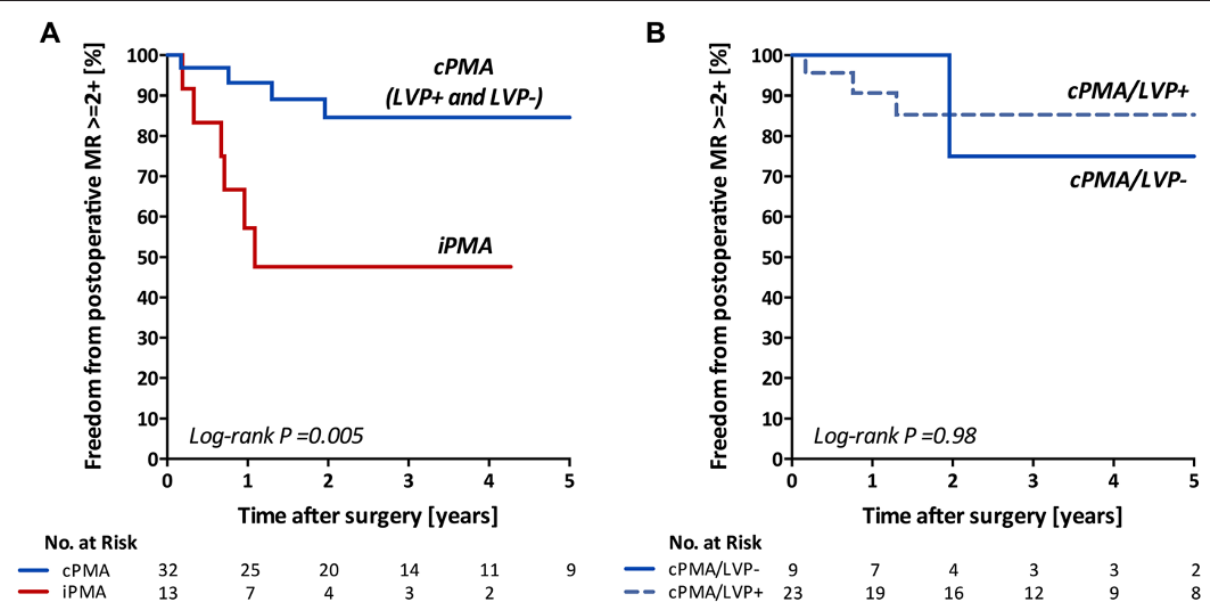

Figure 4 Comparison of freedom from recurrence between complete and incomplete papillary muscle approximation procedures (A) and complete papillary muscle approximation with and without left ventriculoplasty (B). CPMA = complete papillary muscle approximation, iPMA = incomplete PMA, LVP = left ventriculoplasty. 
considering the results of reduction annuloplasty alone in previous reports. In addition, the extent of approximation affected the outcomes. The approximation of the entire papillary muscles was associated with better outcomes than that partially from the tips to mid-parts of the papillary muscles.

The indication for mitral valve repair of ischemic MR still remains controversial because its benefit has not been proven. Wu et al. reported that mitral annuloplasty provided no significant survival benefit for those with moderate to severe MR and LV dysfunction [6]. In contrast, a recent subanalysis of the STICH trial showed that adding mitral valve repair to CABG could be beneficial for those with LV dysfunction and moderate to severe MR compared with CABG alone or medical treatment alone [15]. However, even with mitral valve repair, postoperative mortality is still high in this clinical setting. The 5-year mortality rates were $41 \%, 54 \%$, and $55 \%$ for those with mitral valve repair with CABG, CABG alone, and medication alone, respectively. Mitral valve repair with reduction annuloplasty alone for ischemic MR frequently results in late recurrence of MR. The reported rates of recurrence are between $15 \%$ and 25\% within 6 months and approximately $70 \%$ at 5 years [7]. The issue of durability of the repair may be critical because recurrence of MR is associated with mortality [8]. However, it remains a matter of debate whether mitral valve replacement rather than repair should be selected to prevent recurrence. A recent study demonstrated that there was no significant difference in postoperative survival between mitral valve repair and replacement, though reoperation is frequently associated with repair due to recurrence [16]. In contrast, De Bonis et al. reported that mitral valve repair was preferable to replacement in terms of postoperative survival and improvement of cardiac functions [17]. Thus, reduction annuloplasty alone is not always a suitable surgical option for ischemic MR in terms of the mortality and recurrence of MR, though mitral valve replacement cannot provide a further benefit. The severity of LV remodeling may have a great impact on the results because ischemic MR is a ventricular disease rather than a simple valvular disease. Indeed, a dilated $\mathrm{LV}(\geq 65 \mathrm{~mm})$ is associated with poor outcomes after reduction annuloplasty for ischemic MR [18]. Therefore, an additional procedure such as a ventricular or submitral one, could be required for improvement of the outcomes.

We have adopted papillary muscle approximation to correct mitral valve tethering for functional MR since 2003 [13]. In this procedure, the outward tethering is directly corrected by gathering the papillary muscles together. Apical and posterior tethering can also be improved because the LV dimension decreases due to inward traction of the LV wall by the approximated papillary muscles. Those corrections of tethering may result in a reduction of leaflet tension and restoration of normal leaflet motion. Therefore, we adapt a true-sized annuloplasty ring for mitral valve repair with PMA because a downsized annuloplasty ring may not be necessary after the correction of mitral valve tethering. The use of a true-sized ring might also prevent functional mitral stenosis that could occur after reduction annuloplasty [19].

There are two different types of PMA in terms of the extent of approximation: complete and incomplete PMA. Although procedures similar to both complete $[20,21]$ and incomplete [22] PMA have been proposed, the appropriate concept for this procedure remains unestablished. In this study, we demonstrated that complete PMA was associated with lower mortality and higher durability of repair than incomplete PMA. This is consistent with the report by Jensen et al. They proposed that the traction of the basal papillary muscle was preferable to traction of the papillary muscle tip because instability of the LV wall attached by the papillary muscles might permit LV remodeling and result in recurrence of MR [23]. The inferoposterior LV wall function could play an important role in the treatment of functional MR. Regional remodeling including posteromedial papillary muscles after inferior myocardial infarction causes ischemic MR with a smaller degree of LV dilatation and dysfunction than anterior infarction [24]. In addition, Pocar et al. reported that impaired regional inferoposterior wall motion was a predictor of the recurrence of MR after reduction annulopalsty in patients with ischemic MR [25]. Complete PMA causes regional surgical reverse remodeling at the inferoposterior LV wall and stabilizes the LV wall at the base of the papillary muscles as after papillary muscle imbrication [26]. This could explain why complete PMA was associated with significant improvement of LVEF after surgery but incomplete PMA was not. All the patients enrolled into our study would have had significant regional remodeling in the inferoposterior wall with a great interpapillary muscle distance. Therefore, complete PMA should be considered even with a transvalvular approach to the degree possible. Otherwise, alternative procedures with new approaches, such as extracardiac and interventional approaches, to the basal papillary muscles will be required for the improvement of the results.

Some concomitant procedures such as LVP could bias the results of PMA because LVP causes radical changes of LV geometry and functions, resulting in surgical reverse remodeling of the LV. Although we found no significant difference in mortality and the durability of repair between those with complete PMA/LVP + and those with complete PMA/LVP-, there was an inherent difference in ventricular scar size, which could affect the outcomes. Thus, left ventriculoplasty might improve the results of those with large ventricular scars and diminish the possible difference in outcomes between those with complete PMA/LVP + and 
complete PMA/LVP-. However, there was still a significant difference in mortality between those with incomplete PMA and those with complete PMA/LVP- (log-rank P = 0.047). Therefore, concomitant left ventriculoplasty to some extent influenced the outcomes of complete PMA cases but did not significantly affect our conclusions. In contrast, papillary muscle suspension could modify the effect of PMA. Especially with anterior suspension, further improvement of posterior tethering could be expected. In our study, however, papillary muscle suspension did not demonstrate a significant effect on survival or the durability of repair.

\section{Limitations}

There were several limitations to this study that should be mentioned. First, the small sample size with a variety of surgical procedures might have affected the statistical significance. Because of the long study period with respect to the sample size, a learning curve might affect the outcomes. However, there was no significant difference in mortality between those who underwent surgery in the early (before 2006, $\mathrm{N}=18$ ) and late (after 2007, $\mathrm{N}=27$ ) eras ( $\log$-rank $\mathrm{P}=0.76)$. The rate of freedom from recurrence $\geq 2+$ was also comparable between the groups (logrank $\mathrm{P}=0.11$ ). Second, we did not compare PMA and annuloplasty alone because the baseline characteristics and cardiac parameters in both populations were significantly different in our cohort. Instead, we evaluated the outcomes after PMA compared to the results of annuloplasty alone in previous reports. A future study comparing PMA and annuloplasty with a larger sample size will help further our understanding.

\section{Conclusions}

Complete PMA appears to be associated with a high survival rate and the durability of mitral valve repair for ischemic MR with severe LV remodeling. Approximation of the basal papillary muscles with the surrounding LV wall could be an important concept for the repair of ischemic MR.

\section{Abbreviations}

LV: Left ventricle; LVEF: Left ventricular ejection fraction; LVP: Left ventriculoplasty; MR: Mitral regurgitation; NYHA: New York Heart Association; PMA: Papillary muscle approximation.

\section{Competing interests}

The authors declare that they have no competing interests.

\section{Authors' contributions}

SW conceived and designed the study, collected the patients' data and drafted the manuscript. SK participated in the design of the study and helped to collect the patients' data. YS helped to design the study, draft the manuscript and perform statistical analysis. OT and $\Pi$ participated in the design of the study and helped to draft the manuscript. YM developed the surgical techniques and helped to draft the manuscript. All authors read and approved the final manuscript.

\section{Acknowledgements}

We thank the cardiologists Satoshi Yamada, PhD and Hiroyuki Iwano, PhD for the echocardiographic study.

Received: 9 January 2014 Accepted: 5 May 2014

Published: 3 June 2014

\section{References}

1. Grigioni F, Enriquez-Sarano M, Zehr KJ, Bailey KR, Tajik AJ: Ischemic mitral regurgitation: long-term outcome and prognostic implications with quantitative Doppler assessment. Circulation 2001, 103:1759-1764.

2. Otsuji Y, Handschumacher MD, Schwammenthal E, Jiang L, Song JK, Guerrero JL, Vlahakes GJ, Levine RA: Insights from three-dimensional echocardiography into the mechanism of functional mitral regurgitation: direct in vivo demonstration of altered leaflet tethering geometry. Circulation 1997, 96:1999-2008.

3. Levine RA, Schwammenthal E: Ischemic mitral regurgitation on the threshold of a solution: from paradoxes to unifying concepts. Circulation 2005, 112:745-758.

4. Frater RW: The effects on cordal and leaflet stiffness of severe apical, posterior, and outward papillary displacement in advanced ventricular mechanism heart failure and mitral insufficiency. J Heart Valve Dis 2011, 20:608-618

5. Bach DS, Bolling SF: Early improvement in congestive heart failure after correction of secondary mitral regurgitation in end-stage cardiomyopathy. Am Heart J 1995, 129:1165-1170.

6. Wu AH, Aaronson KD, Bolling SF, Pagani FD, Welch K, Koelling TM: Impact of mitral valve annuloplasty on mortality risk in patients with mitral regurgitation and left ventricular systolic dysfunction. J Am Coll Cardiol 2005, 45:381-387.

7. Magne J, Senechal M, Dumesnil JG, Pibarot P: Ischemic mitral regurgitation: a complex multifaceted disease. Cardiology 2009, 112:244-259.

8. Crabtree TD, Bailey MS, Moon MR, Munfakh N, Pasque MK, Lawton JS, Moazami N, Aubuchon KA, Al-Dadah AS, Damiano RJ Jr: Recurrent mitral regurgitation and risk factors for early and late mortality after mitral valve repair for functional ischemic mitral regurgitation. Ann Thorac Surg 2008, 85:1537-1542.

9. Kuwahara E, Otsuji Y, Iguro Y, Ueno T, Zhu F, Mizukami N, Kubota K, Nakashiki K, Yuasa T, Yu B, Uemura T, Takasaki K, Miyata M, Hamasaki S, Kisanuki A, Levine RA, Sakata R, Tei C: Mechanism of recurrent/persistent ischemic/functional mitral regurgitation in the chronic phase after surgical annuloplasty: importance of augmented posterior leaflet tethering. Circulation 2006, 114:1529-534.

10. Zoghbi WA, Enriquez-Sarano M, Foster E, Grayburn PA, Kraft CD, Levine RA, Nihoyannopoulos P, Otto CM, Quinones MA, Rakowski H, Stewart WJ, Waggoner A, Weissman NJ, American Society of Echocardiography: Recommendations for evaluation of the severity of native valvular regurgitation with twodimensional and Doppler echocardiography. J Am Soc Echocardiogr 2003, 16:777-802.

11. Matsunaga A, Tahta SA, Duran CM: Failure of reduction annuloplasty for functional ischemic mitral regurgitation. J Heart Valve Dis 2004, 13:390-397.

12. Jorapur V, Voudouris A, Lucariello RJ: Quantification of annular dilatation and papillary muscle separation in functional mitral regurgitation: role of anterior mitral leaflet length as reference. Echocardiography 2005, 22:465-472.

13. Matsui Y, Suto Y, Shimura S, Fukada Y, Naito Y, Yasuda K, Sasaki S: Impact of papillary muscles approximation on the adequacy of mitral coaptation in functional mitral regurgitation due to dilated cardiomyopathy. Ann Thorac Cardiovasc Surg 2005, 11:164-171.

14. Matsui Y, Fukada Y, Suto Y, Yamauchi H, Luo B, Miyama M, Sasaki S, Tanabe T, Yasuda K: Overlapping cardiac volume reduction operation. J Thorac Cardiovasc Surg 2002, 124:395-397.

15. Deja MA, Grayburn PA, Sun B, Rao V, She L, Krejca M, Jain AR, Leng Chua Y, Daly R, Senni M, Mokrzycki K, Menicanti L, Oh JK, Michler R, Wróbel K, Lamy A, Velazquez EJ, Lee KL, Jones RH: Influence of mitral regurgitation repair on survival in the surgical treatment for ischemic heart failure trial. Circulation 2012, 125:2639-2648.

16. Lorusso R, Gelsomino S, Vizzardi E, D'Aloia A, De Cicco G, Luca F, Parise O, Gensini GF, Stefano P, Livi U, Vendramin I, Pacini D, Di Bartolomeo R, Miceli A, Varone E, Glauber M, Parolari A, Giuseppe Arlati F, Alamanni F, Serraino F, 
Renzulli A, Messina A, Troise G, Mariscalco G, Cottini M, Beghi C, Nicolini F, Gherli T, Borghetti V, Pardini A, et al: Mitral valve repair or replacement for ischemic mitral regurgitation? The Italian Study on the Treatment of Ischemic Mitral Regurgitation (ISTIMIR). J Thorac Cardiovasc Surg 2013, 145:128-139.

17. De Bonis M, Ferrara D, Taramasso M, Calabrese MC, Verzini A, Buzzatti N, Alfieri O: Mitral replacement or repair for functional mitral regurgitation in dilated and ischemic cardiomyopathy: is it really the same? Ann Thorac Surg 2012, 94:44-51.

18. Braun J, van de Veire NR, Klautz RJ, Versteegh MI, Holman ER, Westenberg $\mathrm{JJ}$, Boersma E, van der Wall EE, Bax JJ, Dion RA: Restrictive mitral annuloplasty cures ischemic mitral regurgitation and heart failure. Ann Thorac Surg 2008, 85:430-436.

19. Kubota K, Otsuji Y, Ueno T, Koriyama C, Levine RA, Sakata R, Tei C: Functional mitral stenosis after surgical annuloplasty for ischemic mitral regurgitation: importance of subvalvular tethering in the mechanism and dynamic deterioration during exertion. J Thorac Cardiovasc Surg 2010, 140:617-623.

20. Hvass $U$, Joudinaud $T$ : The papillary muscle sling for ischemic mitral regurgitation. J Thorac Cardiovasc Surg 2010, 139:418-423.

21. Mandegar MH, Roshanali F, Yousefnia MA, Marzban M: Papillary muscle approximation combined with ventriculoplasty in patients with ischemic cardiomyopathy and functional mitral regurgitation: effects on mitral valve and LV shape. Interact Cardiovasc Thorac Surg 2006, 5:81-84.

22. Rama A, Nappi F, Praschker BG, Gandjbakhch I: Papillary muscle approximation for ischemic mitral valve regurgitation. J Card Surg 2008, 23:733-735.

23. Jensen $\mathrm{H}$, Jensen MO, Smerup MH, Vind-Kezunovic S, Ringgaard S, Andersen NT, Vestergaard R, Wierup P, Hasenkam JM, Nielsen SL: Impact of papillary muscle relocation as adjunct procedure to mitral ring annuloplasty in functional ischemic mitral regurgitation. Circulation 2009, 120:592-98.

24. Kumanohoso T, Otsuji Y, Yoshifuku S, Matsukida K, Koriyama C, Kisanuki A, Minagoe S, Levine RA, Tei C: Mechanism of higher incidence of ischemic mitral regurgitation in patients with inferior myocardial infarction: quantitative analysis of left ventricular and mitral valve geometry in 103 patients with prior myocardial infarction. J Thorac Cardiovasc Surg 2003, 125:135-143.

25. Pocar M, Passolunghi D, Moneta A, Di Mauro A, Bregasi A, Mattioli R, Donatelli F: Baseline left ventricular function and surgical annular stiffening to predict outcome and reverse left ventricular remodeling after undersized annuloplasty for intermediate-degree ischemic mitral regurgitation. J Thorac Cardiovasc Surg 2010, 139:1529-1538.

26. Menicanti L, Di Donato M, Frigiola A, Buckberg G, Santambrogio C, Ranucc $M$, Santo D, Group R: Ischemic mitral regurgitation: intraventricular papillary muscle imbrication without mitral ring during left ventricular restoration. J Thorac Cardiovasc Surg 2002, 123:1041-1050.

doi:10.1186/1749-8090-9-98

Cite this article as: Wakasa et al:: The extent of papillary muscle approximation affects mortality and durability of mitral valve repair for ischemic mitral regurgitation. Journal of Cardiothoracic Surgery 2014 9:98.

\section{Submit your next manuscript to BioMed Central and take full advantage of:}

- Convenient online submission

- Thorough peer review

- No space constraints or color figure charges

- Immediate publication on acceptance

- Inclusion in PubMed, CAS, Scopus and Google Scholar

- Research which is freely available for redistribution

Submit your manuscript at www.biomedcentral.com/submit
( Biomed Central 